Supporting information

\title{
Lanthanide Coordination Polymer Nanoparticles as an Excellent Artificial Peroxidase for Hydrogen Peroxide Detection
}

\author{
Hui-Hui Zeng, ${ }^{1,2}$ Wei-Bin Qiu, ${ }^{1}$ Li Zhang, ${ }^{1}$ Ru-Ping Liang, ${ }^{1}$ Jian-Ding Qiu ${ }^{1,2} *$ \\ Department of Chemistry, Nanchang University, Nanchang 330031, China \\ Department of Materials and Chemical Engineering, Pingxiang University, Pingxiang 337055, China \\ * Tel. Fax: +86 791 83969518. E-mail: jdqiu@ncu.edu.cn
}

\section{TABLE OF CONTENTS}

1. PL spectra of NTP-Ce-Tris CPNs (NTP = ATP, GTP, CTP, TTP, and UTP) (Figure S1)

2. Studies on optimum synthesis conditions of ATP-Ce-Tris CPNs (Figure S2)

3. UV-vis absorption spectra of cerium nitrate, ATP, Tris-HCl, Tris-Ce, ATP-Tris, ATP-Ce, ATP-Ce-Tris (Figure S3)

4. PL spectra of the cerium nitrate, Tris-Ce, ATP-Ce upon $\mathrm{H}_{2} \mathrm{O}_{2}$ (Figure S4)

5. UV-vis absorption spectra of $\mathrm{Ce}\left(\mathrm{NO}_{3}\right)_{3}$, ATP-Ce, and Tris-Ce upon $\mathrm{H}_{2} \mathrm{O}_{2}$ (Figure S5)

6. Studies on optimal ATP-Ce-Tris CPNs concentration for $\mathrm{H}_{2} \mathrm{O}_{2}$ detection (Figure S6)

7. Reaction time study (Figure S7)

8. Studies on Effect of $\mathrm{pH}$ upon $\mathrm{H}_{2} \mathrm{O}_{2}$ detection (Figure $\mathrm{S} 8$ )

9. Selectivity study (Figure S9)

10. Studies on glucose detection from real blood samples (Table S1)

11. The method of determining detection limit (LOD) 


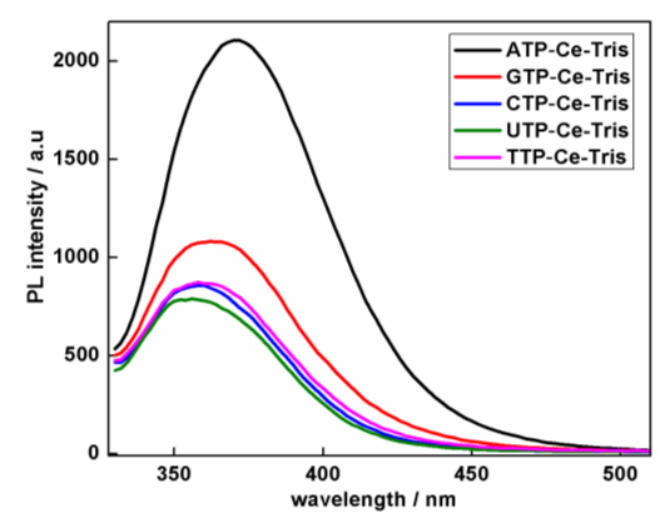

Figure S1 PL spectra of the ATP-Ce-Tris CPNs (black line), GTP-Ce-Tris CPNs (red line), CTP-Ce-Tris CPNs (blue line), UTP-Ce-Tris CPNs (green line) and TTP-Ce-Tris CPNs (pink line) in Tris- $\mathrm{HCl}$ buffer $(50 \mathrm{mM}, \mathrm{pH} 7.4), \lambda \mathrm{ex}=310 \mathrm{~nm}$. The concentrations of ATP-Ce-Tris, GTP-Ce-Tris, CTP-Ce-Tris, UTP-Ce-Tris, TTP-Ce-Tris CPNs were $0.4 \mathrm{mM}$.
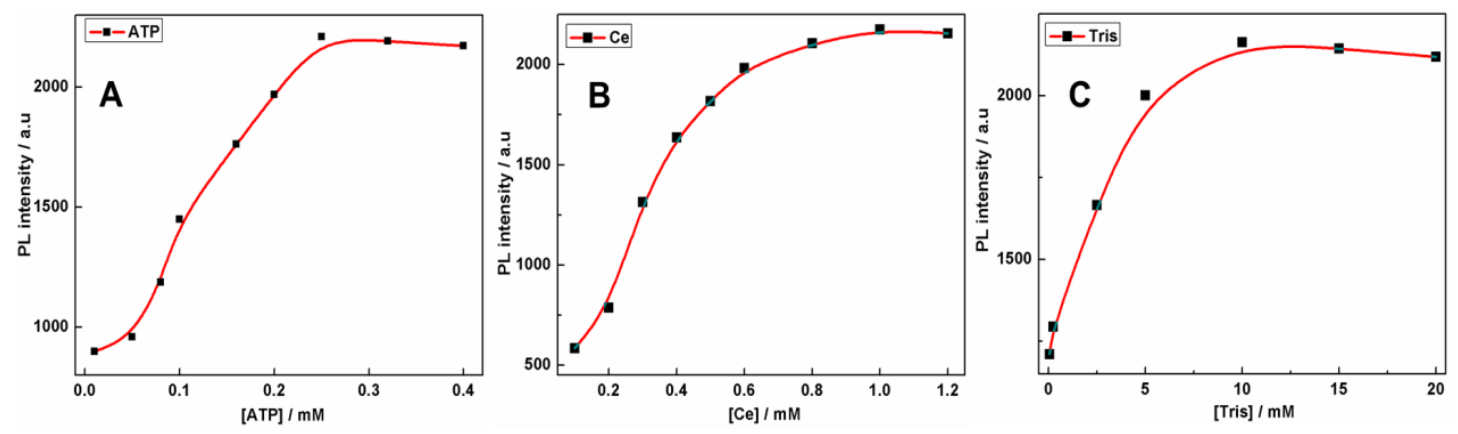

Figure S2 Dependence of the PL intensity of ATP-Ce-Tris CPNs on the concentrations of (A) ATP, (B) Ce, and (C) Tris.

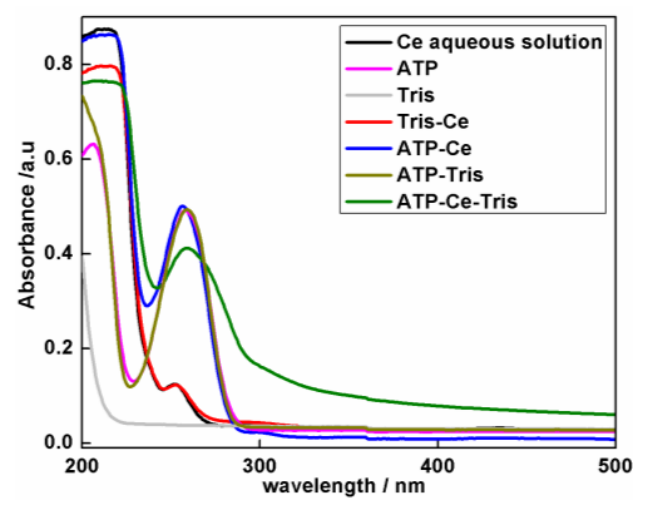

Figure S3 UV-vis absorption spectra of the cerium nitrate aqueous solution (black line), ATP aqueous solution (pink line), Tris-HCl aqueous solution (gray line), Tris-Ce aqueous solution (red line), ATP-Ce aqueous solution (blue line), ATP-Tris aqueous solution (light green line), ATP-Ce-Tris aqueous solution (green line). The concentrations of cerium nitrate, Tris-Ce, ATP-Ce, ATP-Ce-Tris CPNs were $0.4 \mathrm{mM}$. 


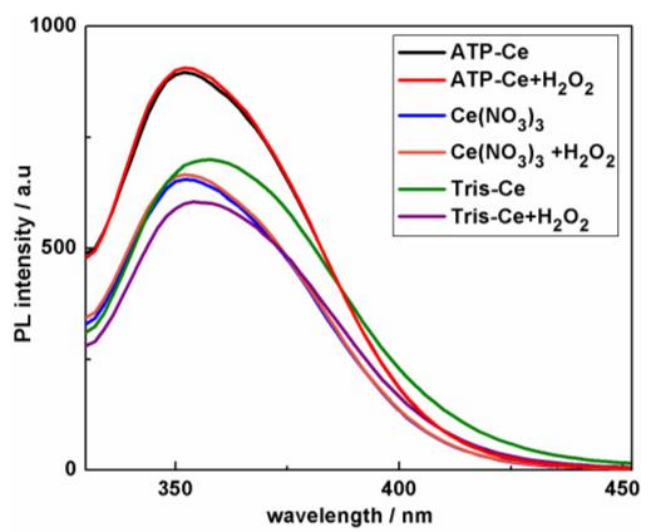

Figure S4 PL spectra of the ATP-Ce aqueous solution (black and red line), $\mathrm{Ce}\left(\mathrm{NO}_{3}\right)_{3}$ (blue and orange line), Tris-Ce aqueous solution (green and purple line) in the absence and presence of $\mathrm{H}_{2} \mathrm{O}_{2}(10 \mu \mathrm{M})$ in Tris-HCl buffer $(50 \mathrm{mM}, \mathrm{pH} 7.4), \lambda \mathrm{ex}=310 \mathrm{~nm}$. The concentrations of cerium nitrate, Tris-Ce, ATP-Ce were $0.4 \mathrm{mM}$.

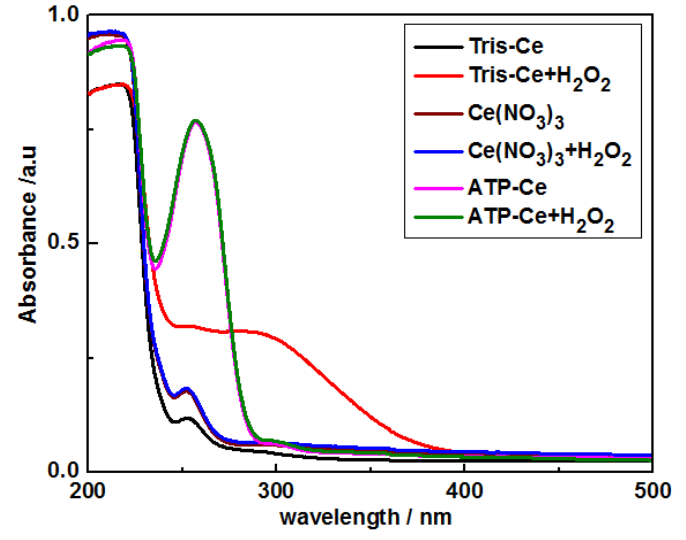

Figure S5 UV-vis absorption spectra of the Tris-Ce aqueous solution (black and red line), $\mathrm{Ce}\left(\mathrm{NO}_{3}\right)_{3}$ (purple and blue line), ATP-Ce aqueous solution (pink and green line) in the absence and presence of $\mathrm{H}_{2} \mathrm{O}_{2}(1 \mathrm{mM})$. The concentrations of Tris-Ce, $\mathrm{Ce}\left(\mathrm{NO}_{3}\right)_{3}$, ATP-Ce were $0.4 \mathrm{mM}$.
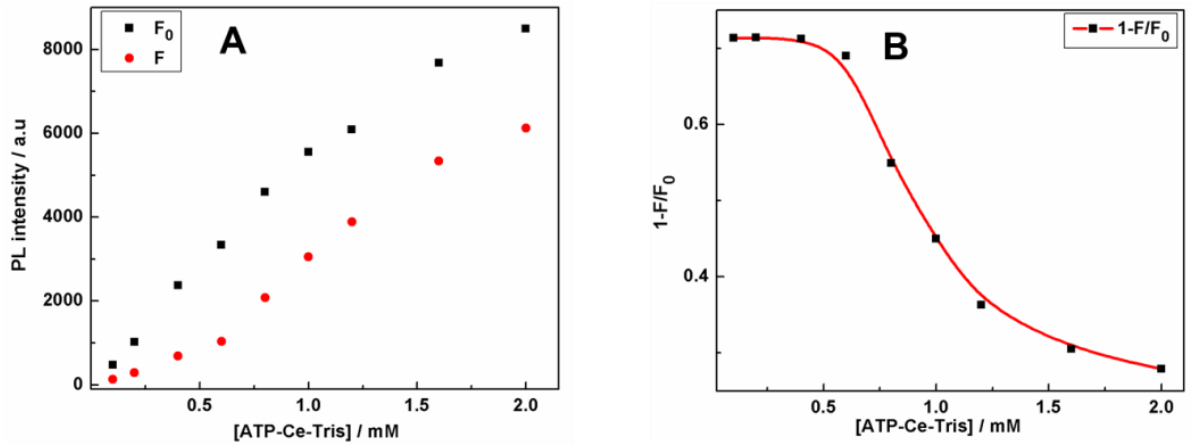

Figure S6 (A) The PL intensity of ATP-Ce-Tris CPNs with different concentration before $\left(\mathrm{F}_{0}\right)$ and after (F) adding $\mathrm{H}_{2} \mathrm{O}_{2}(10 \mu \mathrm{M})$. (B) The FL quenching efficiency $\left(1-\mathrm{F} / \mathrm{F}_{0}\right)$ of different concentrations of ATP-Ce-Tris CPNs upon $\mathrm{H}_{2} \mathrm{O}_{2}(10 \mu \mathrm{M})$. 


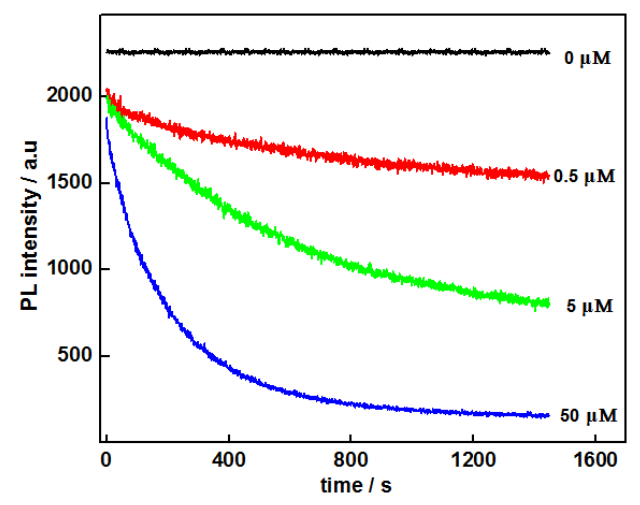

Figure S7 Time-dependent PL responses of ATP-Ce-Tris CPNs $(0.4 \mathrm{mM})$ upon addition of different concentrations of $\mathrm{H}_{2} \mathrm{O}_{2}, 0 \mu \mathrm{M}$ (black line), $0.5 \mu \mathrm{M}$ (red line), $5 \mu \mathrm{M}$ (green line), $50 \mu \mathrm{M}$ (blue line).
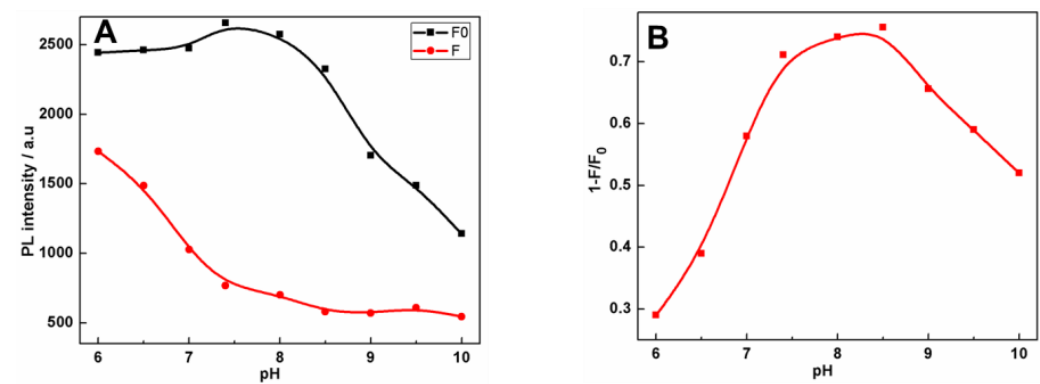

Figure S8 (A) Effect of pH on the PL intensity of ATP-Ce-Tris CPNs $(0.4 \mathrm{mM})$ in the absence (black dot) and presence (red dot) of $\mathrm{H}_{2} \mathrm{O}_{2}(10 \mu \mathrm{M})$. (B) The fluorescence quenching efficiency (1-F/F $\mathrm{F}_{0}$ ) of ATP-Ce-Tris CPNs toward $\mathrm{H}_{2} \mathrm{O}_{2}$, where $\mathrm{F}_{0}$ and $\mathrm{F}$ are the PL intensities of ATP-Ce-Tris CPNs at $370 \mathrm{~nm}$ before and after adding $\mathrm{H}_{2} \mathrm{O}_{2}$, respectively.

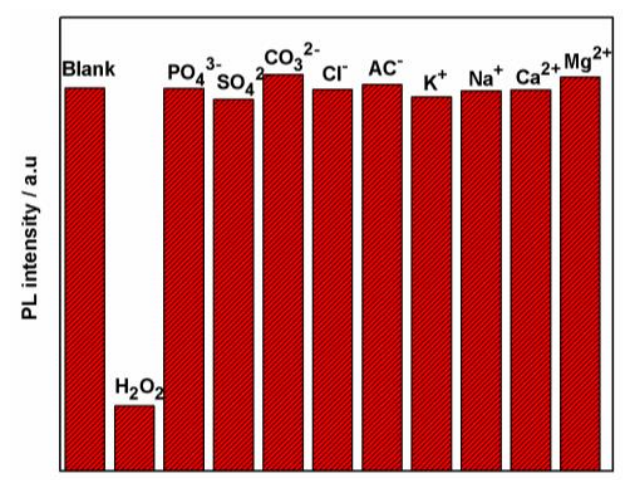

Figure S9 Selectivity competition experiments for ATP-Ce-Tris CPNs $(0.4 \mathrm{mM})$ toward different interferences in Tris- $\mathrm{HCl}$ buffer $\left(50 \mathrm{mM}, \mathrm{pH}\right.$ 7.4). $\mathrm{H}_{2} \mathrm{O}_{2}$ was at a concentration of $5 \mu \mathrm{M}$; other control substances are at a concentration of $0.1 \mathrm{mM}$. 
Table S1. Results for detection of glucose from real blood samples

\begin{tabular}{ccccc}
\hline Samples & $\begin{array}{c}\text { Added } \\
(\mathrm{mM})\end{array}$ & $\begin{array}{c}\text { Detected } \\
(\text { mean, } \mathrm{mM})\end{array}$ & $\begin{array}{c}\text { RSD } \\
(\mathrm{n}=3, \%)\end{array}$ & $\begin{array}{c}\text { Recovery } \\
(\%)\end{array}$ \\
\hline 1 & 0 & 4.92 & 2.3 & \\
2 & 1 & 5.98 & 3.1 & 106 \\
3 & 2 & 6.89 & 1.9 & 98.5 \\
4 & 3 & 8.03 & 3.0 & 103.7 \\
\hline
\end{tabular}

Serum samples were diluted 100-folds. Mean value of three determinations. The detection concentration is $4.90 \mathrm{mM}$ by the local hospital.

The method of determining detection limit (LOD):

In this work, the LOD is calculated by using the following formula (1): ${ }^{1-3}$

$$
\mathrm{LOD}=3 \sigma / \mathrm{S}
$$

Where ' $S$ ' is the slope of calibration curve, and ' $\sigma$ ' is the standard deviation of 11 blank samples, which is calculated by using the following formula (2):

$$
\sigma=\sqrt{\frac{1}{n-1} \sum_{i=1}^{n}\left(l_{i}-\bar{L}\right)^{2}}
$$

Where ' $l_{i}$ ' is the PLintensity of each blank sample ( $\left.i=1-11\right)$, and ' $L$ ' is the average PL intensity of 11 blank samples ( $\mathrm{n}=11)$.

For example, in the calculation of LOD of glucose detection, ' $\mathrm{S}$ ' is 0.46 , which is achieved from the calibration curve equation, and the ' $\sigma$ ' is about $1 \%$, which is obtained by the standard deviation of 11 blank samples. By using formula (1), the LOD of glucose detection can be calculated and equal $65 \mathrm{nM}$.

\section{References:}

(1) Derayea, S. M. Anal. Methods 2014, 6, 2270-2275.

(2) Wee, S. S.; Ng, Y. H.; Ng, S. M. Talanta 2013, 116, 71-76.

(3) Liu, Z.; He, W.; Pei, M.; Zhang, G. Chem. Commun. 2015, 51, 14227-14230. 